\title{
Sliding Mode Control-Based Chaos Stabilization in PM DC Motor Drive
}

\author{
Mohammed Abbas Abdullah \\ Electrical Engineering \\ Department \\ Basrah University \\ Basrah, Iraq. \\ m.abbas.iraq@gmail.com
}

\author{
Fadhil Rahma Tahir \\ Electrical Engineering \\ Department \\ Basrah University \\ Basrah, Iraq. \\ fadhilrahma@hotmail.com
}

\author{
Khalid M. Abdul-Hassan \\ Electrical Engineering \\ Department \\ Basrah University \\ Basrah, Iraq. \\ Khmh7447@gmail.com
}

\begin{abstract}
In this paper, a model of PM DC Motor Drive is presented. The nonlinear dynamics of PM DC Motor Drive is discussed. The drive system shows different dynamical behaviors; periodic, quasi-period, and chaotic and are characterized by bifurcation diagrams, time series evolution, and phase portrait. The stabilization of chaos to a fixed point is adopted using slide mode controller (SMC). The chaotic dynamics are suppressed and the fixed point dynamics are observed after the activation of proposed controller. Numerical simulation results show the effectiveness of the proposed method of control for stabilization the chaos and different disturbances in the system.
\end{abstract}

Index Terms- PM DC DRIVE, CHAOS, SUPPRESSING OF CHAOS, SLIDE MODE CONTROL.

\section{INTRODUCTION}

Chaos originates from nonlinear interactions in a system and it is very sensitive to the system configuration and initial conditions. Tiny variations of these parameters result in great changes in chaotic signals [1,2]. A great deal of research, both theoretical and experimental, has been performed on nonlinear electronic circuits. This is because, nonlinear electric circuits provide a convenient framework for undertaking a systematic exploration of mechanisms underlying the onset of chaos. Nonlinear oscillators and electronic circuits subjected to periodic forcing can produce different behaviors like periodicity and period-doubling bifurcation route to chaos[3-5].

In PM DC motor drive the switch provides the nonlinearity in the system. In the nominal steady state behavior, the PM DC motor drive system response is continuous wave with small periodic ripple, about mean value close to reference state, at the same frequency of pulse width modulation (PWM). This operating behavior is referred to a period-1 mode. Due to the nonlinearity, the system dynamics are being sensitive dependence to any small variations in system parameters values. As any system parameter is being varied, the nominal orbit loses stability and subharmonics (quasiperiodic) orbit emerges due to bifurcation. Further variation leads to emerge of a chaotic orbit (an aperiodic)[6-12].

Chaos control is realizing in how to control the chaotic system to the periodic orbit or fixed point behaviors with the system parameters remained, because the system parameters cannot be changed objectively. To achieve control of the undesirable chaos in the PM DC motor drive, typical methods have been proposed. For example, OttGrebogi-Yorke (OGY) and time delay feedback control (TDFC) methods. By applying the control method the chaotic system can be stabilized into period-1 mode[6,7,13-16]. the chaos and different disturbances in the system. slide mode control (SMC) method very robust control and insensitive to parameters variations and disturbance, fast response and the system exponentially dynamics converges to fixed point from any initial condition. The SMC has been used to suppress of chaos in DC-DC converters applications [9-14]. 


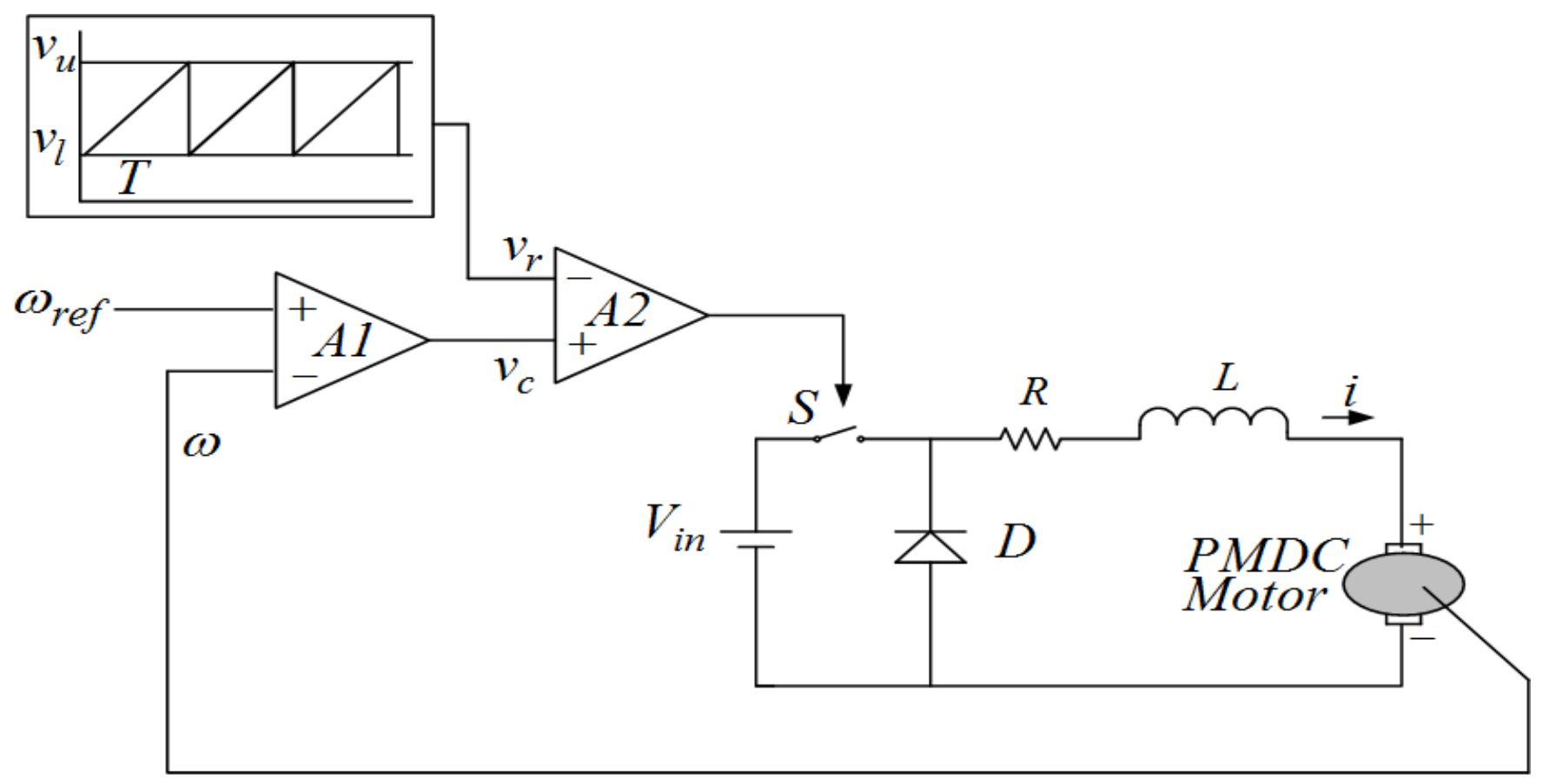

Fig. 1: Schematic diagram of voltage-controlled PM DC motor drive system.

The presented control method in this paper is nonlinear control sliding mode control (SMC) to stabilize the system dynamics from chaos to stable operation. The dynamics features of PM DC motor drive system have been investigated through the bifurcation diagram, time series evaluation, and phase portrait. In addition, the controlled system under different disturbances is examined.

This paper is arranged as follow; after this introduction, Section II describes PM DC motor drive model. In Section III, the nonlinear dynamics in PM DC motor drive are addressed. Section IV presents the suppressing of chaos via SMC control technique and in Section $V$ the system response under disturbances is addressed using SMC. Finally, Section VI conclude this paper.

\section{PM DC MOTOR DRIVE MODEL}

A voltage mode control is proposed to speed control of PM DC motor drive, the schematic diagram of the system as shown in Fig. 1. The PWM signal is varying continously to ensure that the actual speed is tracking the refrense speed [7]. Assume that the operational amplifier $A 1$ has a feedback gain $h$, the control signal $v_{c}$ can be described as:

$v_{c}(t)=h\left(\omega_{\text {ref }}-\omega(t)\right)$

where $\omega_{\text {ref }}$ and $\omega(t)$ are the reference and actual speeds of motor, respectively. The ramp voltage $v_{r}$ is expressed by:

$v_{r}(t)=v_{l}+\left(v_{u}-v_{l}\right) t / T$

where $v_{l}$ and $v_{u}$ are the lower and upper threshold voltages of ramp signal, respectively, and $T$ is its period. $v_{c}$ and $v_{r}$ are fed into comparator $A 2$ which give the signal to turn the power switch $S$ on or off. Thus, the system equation can be divided into two modes as given by: 
Mode1: $v_{r}<v_{c}$

$\frac{d \omega}{d t}=\frac{1}{J}\left(K_{t} i-T_{L}-B \omega\right)$

$\frac{d i}{d t}=\frac{1}{L}\left(V_{i n}-i R-K_{e} \omega\right)$

Mode2: $v_{r} \geq v_{c}$

$\frac{d \omega}{d t}=\frac{1}{J}\left(K_{t} i-T_{L}-B \omega\right)$

$\frac{d i}{d t}=\frac{1}{L}\left(-i R-K_{e} \omega\right)$

The power switch $S$ is turn on, when $v_{r}<v_{c}$. The freewheeling diode is reverse biased and the system dynamic is describe by (3). While, the switch is turn off when $v_{r} \geq v_{c}$. The freewheeling diode forward biased and the armature current freewheeling through it and the system dynamic is describe by (4).

Where

$V_{\text {in }}:$ Supply voltage

$\omega$ : Shaft speed

$i \quad$ : armature current

$R$ : armature resistance

$L$ : armature inductance

$J$ : Moment of inertia

$B$ : Viscous friction

$K_{t}$ : Torque constant

$K_{e}:$ Back EMF constant

$T_{L}$ : Load torque.

\section{NON LINEAR DYNAMICS IN PM DC MOTOR DRIVE SYSETM}

To assess the propoer operation of PM DC motor drive system feedback control, the nonlinear dyanimcs of current and speed are studied with respect to supply voltage $V_{i n}$. The nonlinear characteristics of the current and speed can be observed by the bifurcation diagram and phase portraite. In this paper, numerical simulations of the current and speed of the PM DC motor drive described by (3) and (4) have been achieved. Parameters of PM DC motor drive used in the simulation are [11];

$$
\begin{aligned}
& B \quad=1 * 10^{-4} \mathrm{~N} \cdot \mathrm{m} / \mathrm{rad} / \mathrm{s} \\
& J \quad=1.0388 * 10^{-5} \mathrm{~N} \cdot \mathrm{m} / \mathrm{rad} / \mathrm{s}^{2} \\
& L \quad=0.4 \mathrm{mH} \\
& R \quad=1.1 \Omega \\
& K_{t}=0.05 \mathrm{~N} . \mathrm{m} / \mathrm{A} \\
& K_{e}=0.05 \mathrm{~V} . \mathrm{s} / \mathrm{rad} \\
& T_{L}=0.1 \mathrm{~N} . \mathrm{m} \\
& \omega_{r e f}=100 \mathrm{rad} / \mathrm{sec} \\
& T \quad=0.1 \mathrm{msec}
\end{aligned}
$$

The bifuraction diagram techniuuqe is widely used to describe the transtion from periodic motion to chaotic motion for a dynamic system. Fig. 2 (a) and (b) shows the bifurcation diagram of current and speed with respect to supply voltage in the range of $V_{\text {in }} \in[20,28]$. We can see that the current and speed keep stable periodic oscillation orbit for $V_{\text {in }}<20.65$. It is noticed that the current and speed orbits lose stability via period-doubling bifurcation, lead to the emerge of period-2 orbit when $V_{\text {in }}=20.65$. As $V_{\text {in }}$ further increased, the system undergoes to perioddoubling bifurcation cascaded as $V_{i n}=24.86$ period-4 occurs. The periodic orbit lost stability and begins to repel. As $V_{\text {in }} \in[25.5,27.9]$, the system exhibits chaotic behavior. In the region $27.9 \leq V_{\text {in }} \leq 27.95$, an intermittent period-3 window appeared which also undergoes perioddoubling rout to chaos.

Fig.3 depicts the time response of the armature current $i$. As shown in Fig.3 (a), it can be notice that $i$ oscillates with constant period when $V_{\text {in }}=20 \mathrm{~V}$. Along with the increasing bifurcation parameter, the $i$ exhibits the stable period-2 and period-4 as shown in Fig. 3(b) and (c), respectively. Fig. 3(d) shows that the current of armature and speed enter into chaotic domain with $V_{\text {in }}=26 \mathrm{~V}$.

The phase portrait of the speed versus armature current was provided in Fig. 4. Also, it indicates a transition from periodic oscillation dynamics behavior into chaotic dynamics. It can be seen that the periodic oscillations occurs when $V_{\text {in }}$ equal to $20 \mathrm{~V}, 21 \mathrm{~V}$, and $25 \mathrm{~V}$ as shown in Fig. 4 (a), (b), and (c), whereas the chaotic oscillation can be observed when $V_{\text {in }}$ is $26 \mathrm{~V}$, as shown in Fig.4(d). 


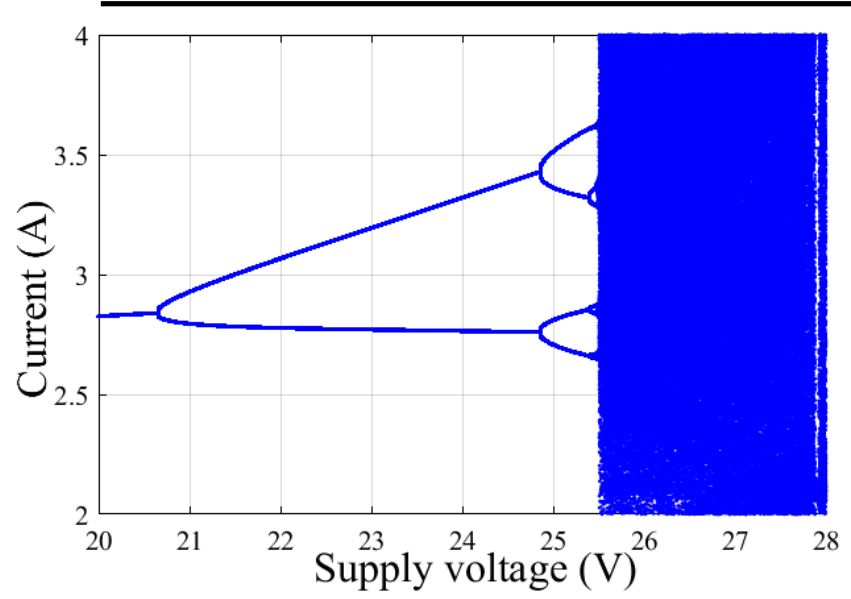

(a)

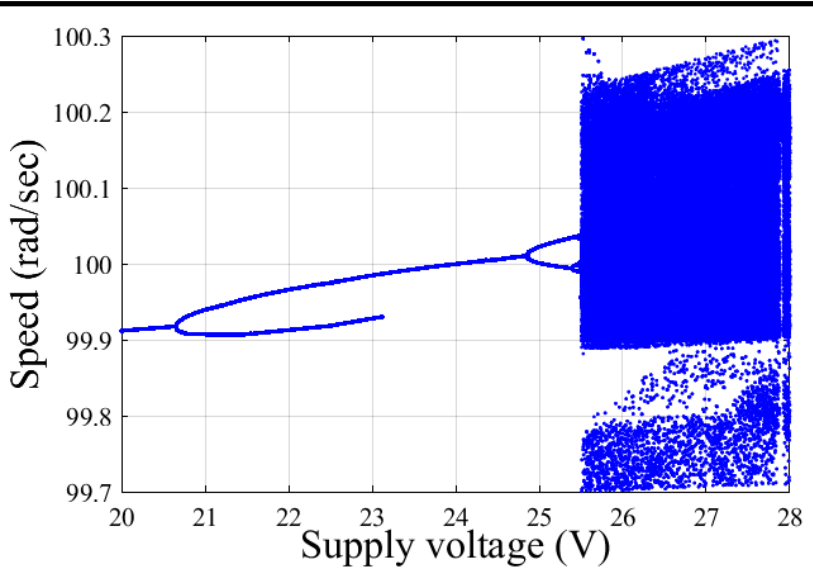

(b)

Fig. 2: Bifurcation diagram of current and speed of (3) and (4) with supply voltage. $h=3$.

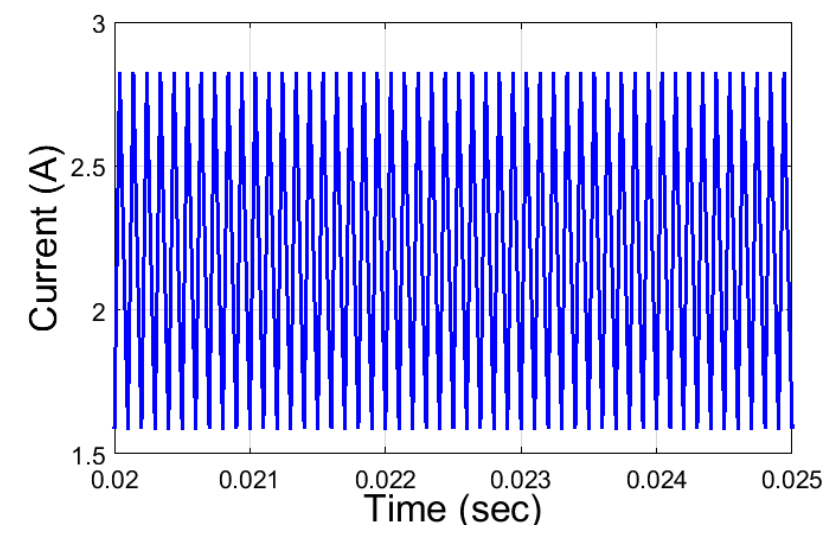

(a)



(c)

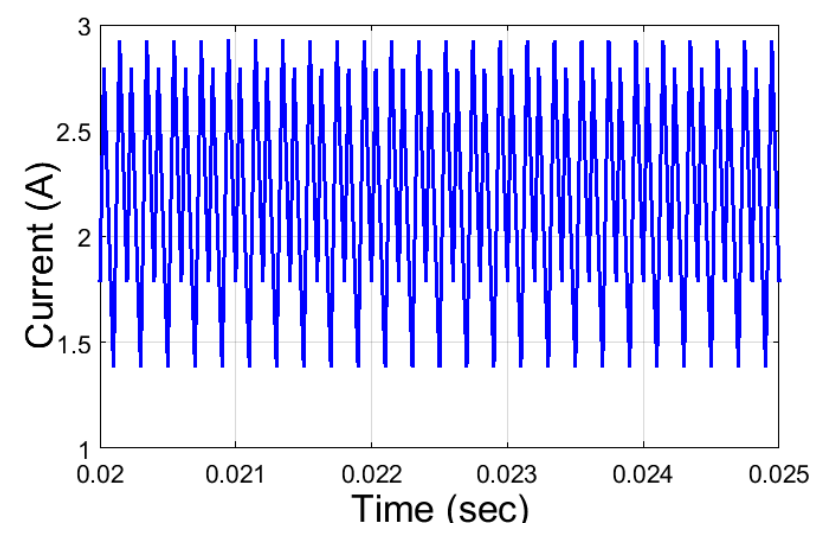

(b)

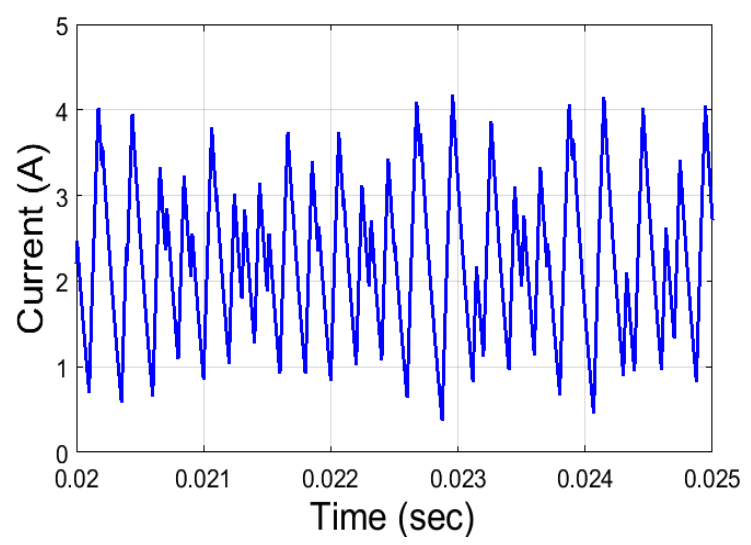

(d)

Fig. 3:Time response of armature current $i$.(a) $V_{\text {in }}=20 \mathrm{~V}$, (b) $V_{\text {in }}=21 \mathrm{~V}$, (c) $V_{\text {in }}=25 \mathrm{~V}$, (d) $V_{\text {in }}=26 \mathrm{~V}$. 


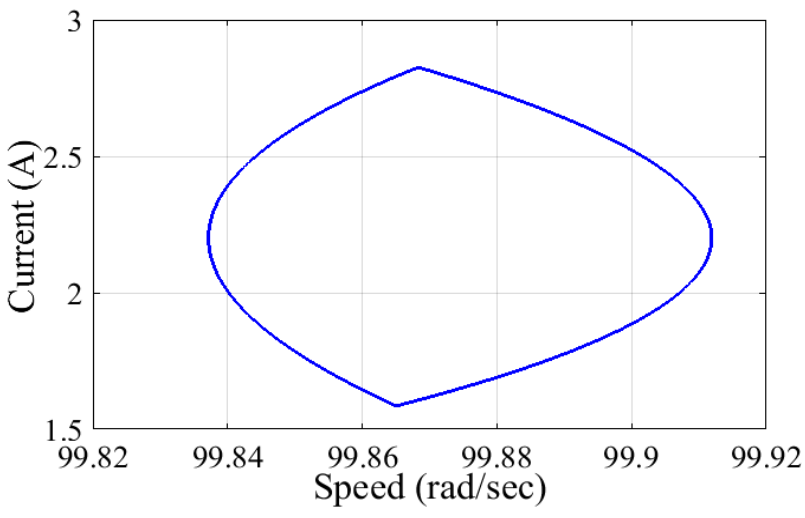

(a)

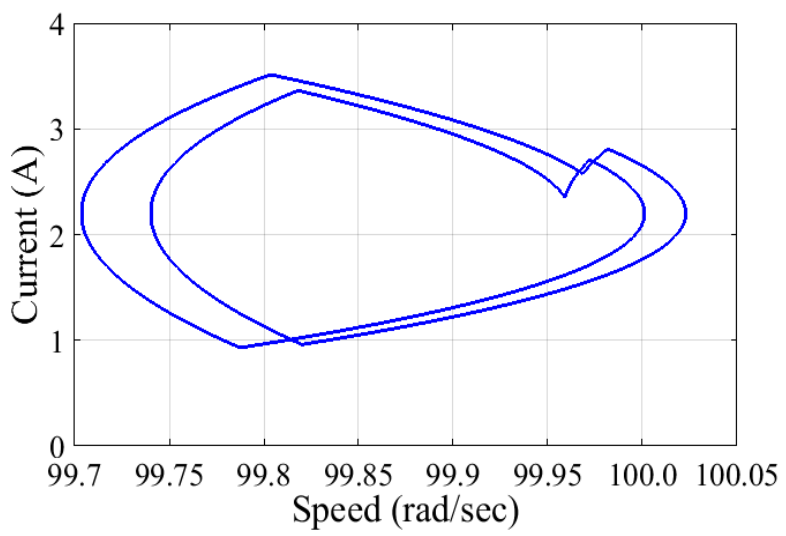

(b)

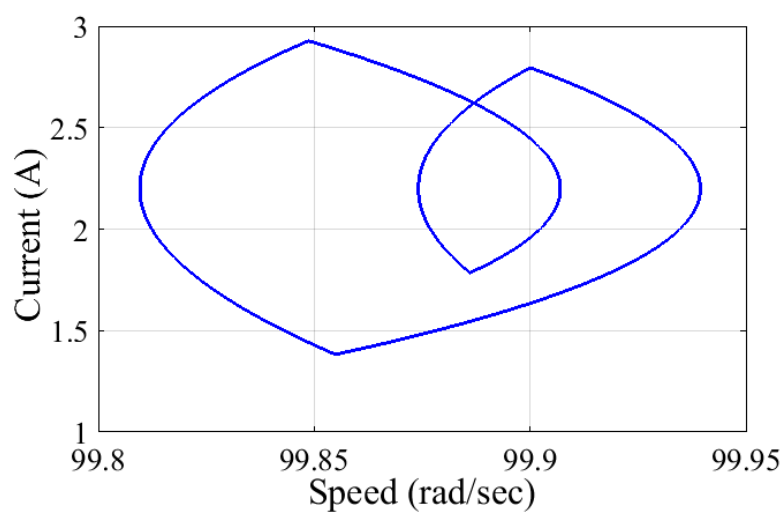

(b)

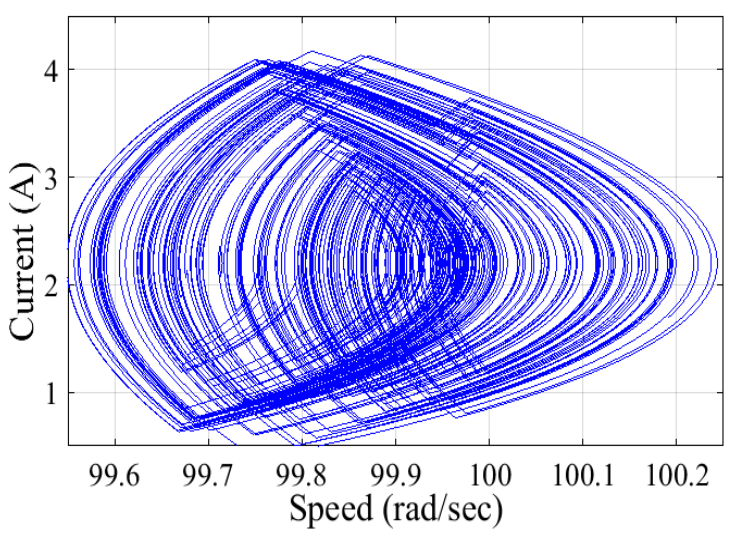

(d)

Fig. 4:Phase portrait of speed versus armature current. Period-doubling bifurcation. (a)Period-1; $V_{i n}=20 \mathrm{~V}$, (b)Period-2; $V_{i n}=21 V$, (c)Period-4; $V_{i n}=25 V$, (d)Chaotic; $V_{\text {in }}=26 V . h=3$.

\section{CHAOS SUPPRESESING VIA SMC}

The sliding mode control (SMC) is one of the most efficient method to suppress the chaos. The steps of design of SMC can be expressed as:

i-define a sliding surface

ii-design a discontinuous control that forces system dynamics to asymptote the sliding surface from any initial condition.

A modified SMC based on speed measurement only has been used. The implementation structure of the SMC for stabilized the chaotic dynamics in PM DC drive system illustrated in Fig. 5. Suppose that the speed tracking error is $x=e=\omega_{\text {ref }}-\omega$ and error dynamics can be expressed by state space form as follows: $\dot{x}=y$

$\dot{y}=-a_{1} x-a_{2} y+f(t)-b u$

where $a_{1}=\frac{R B+K_{e} K_{t}}{J L}, a_{2}=\frac{R J+B L}{J L}, c=\frac{1}{J}, d=\frac{R}{J L}$, and $b=\frac{K_{t}}{J L}$ are constants and

$f(t)=\ddot{\omega}+a_{2} \dot{\omega}_{r e f}+a_{1} \omega_{r e f}+\mathrm{d} T_{L}+c \dot{T}_{L}$

The sliding surface and discontinuous control is designed as:

$s=\left(\lambda+\frac{d}{d t}\right) e$

$u=V_{\text {in }} \operatorname{sign}(s)$

Where

$\lambda$ is the rate of convergence. 


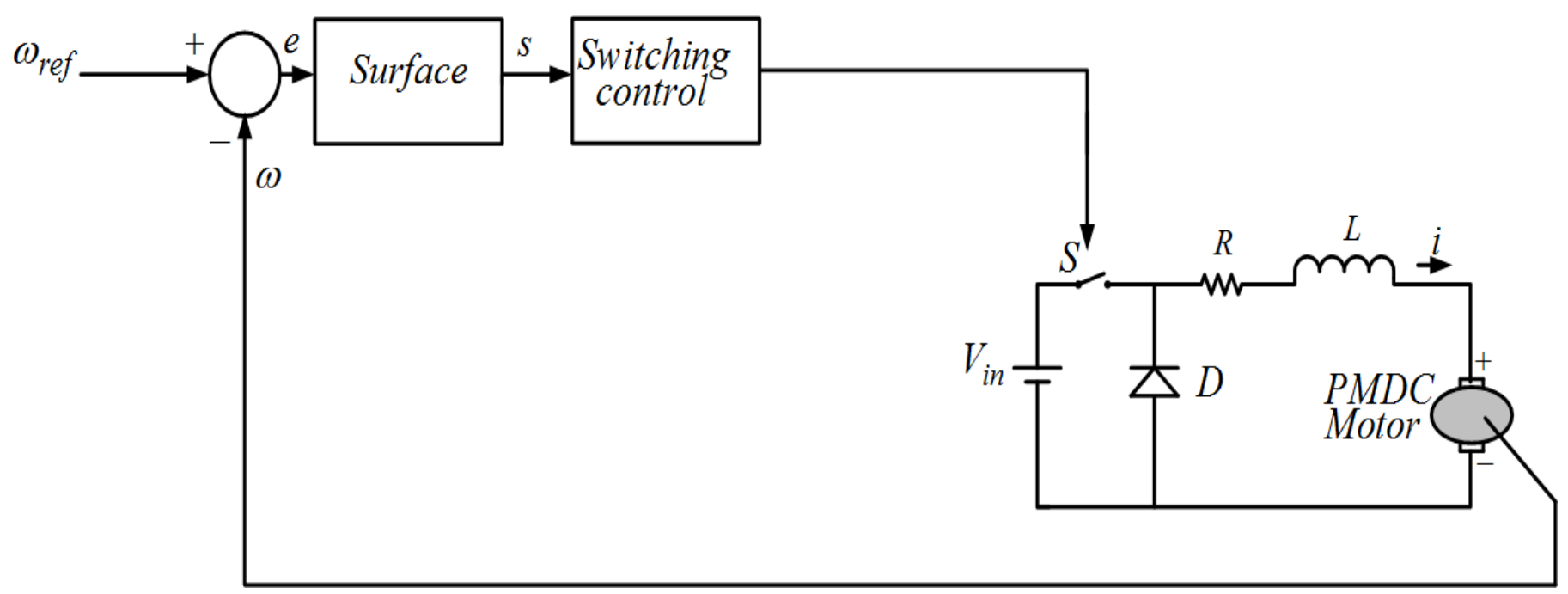

Fig. 5: Schematic diagram of voltage-controlled PM DC motor drive system.



(a)

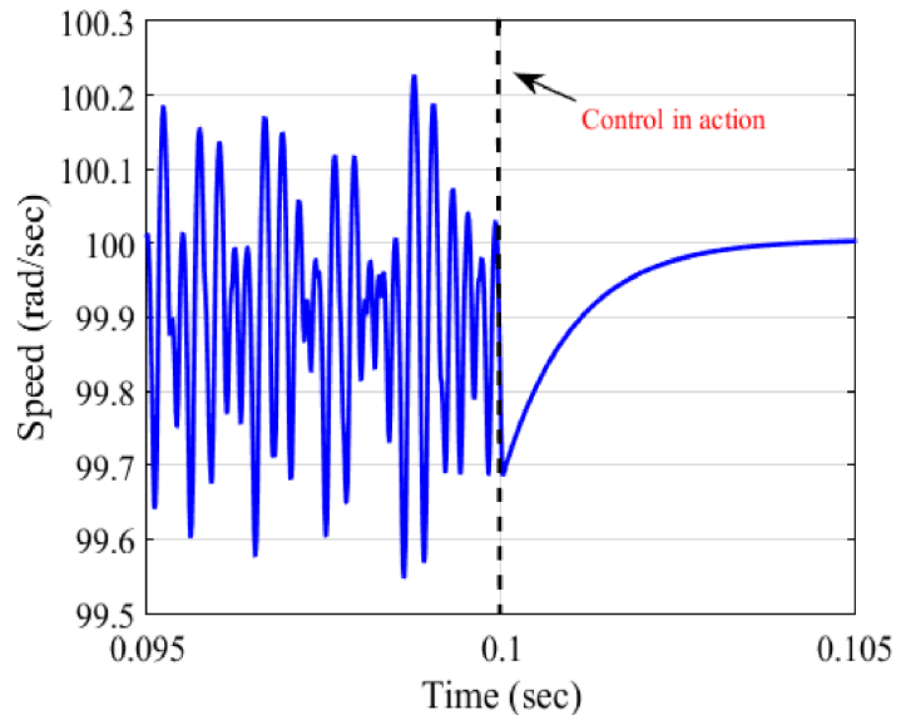

(b)

Fig. 6: Time series waveforms of current and speed with and without control.(a) current and (b) speed. 


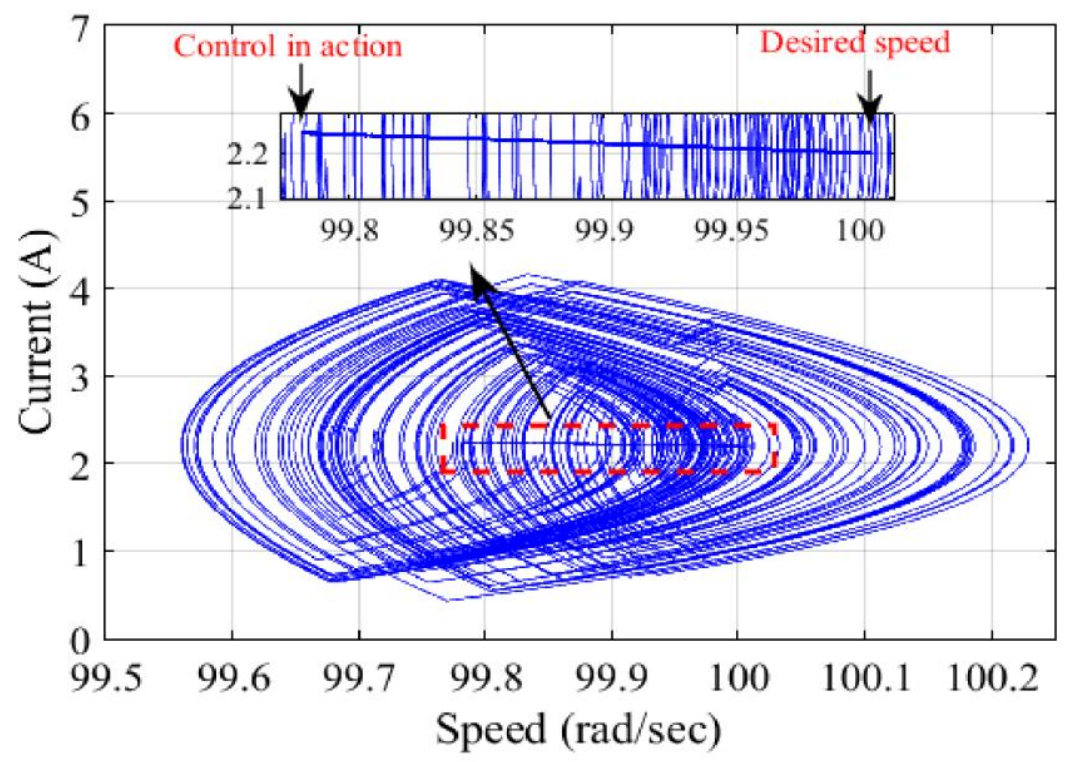

Fig. 7: Phase portrait of speed vs. current when the SMC controller suppressed the chaos from dynamics.

To enforce the trajectory for moving on sliding surface, the condition should be satisfied is $s \dot{s}<0$.

From (5) and (7), the condition is satisfied when

$V_{\text {in }}>\frac{1}{b}\left|-a_{1} x_{1}-\left(a_{2}-\lambda\right) x_{2}+f(t)\right|$

The rate of convergence $\lambda$ should be selected in suitable manner. Low rising time system response and high overshoot are observed when $\lambda$ is large. While overshoot in the system response and large rising time when $\lambda$ is small.

After activation the proposed control, the speed converge to the desired fixed point in 5 msec and current go to fixed point after 2.5 msec, The current and the speed trajectory under the controlled suppress the chaos are shown in Fig. 6, phase portrait of speed vs. current shown in Fig. 7.

\section{THE SYSTEM RESPONSE UNDER DISTURBANCES}

Figure 8, refers the system response under the load variation. When the load is $0.3 N$ N.m with \pm 0.2 N.m disturbance, the speed dynamic exhibits fast recovery after $3 \mathrm{msec}$.

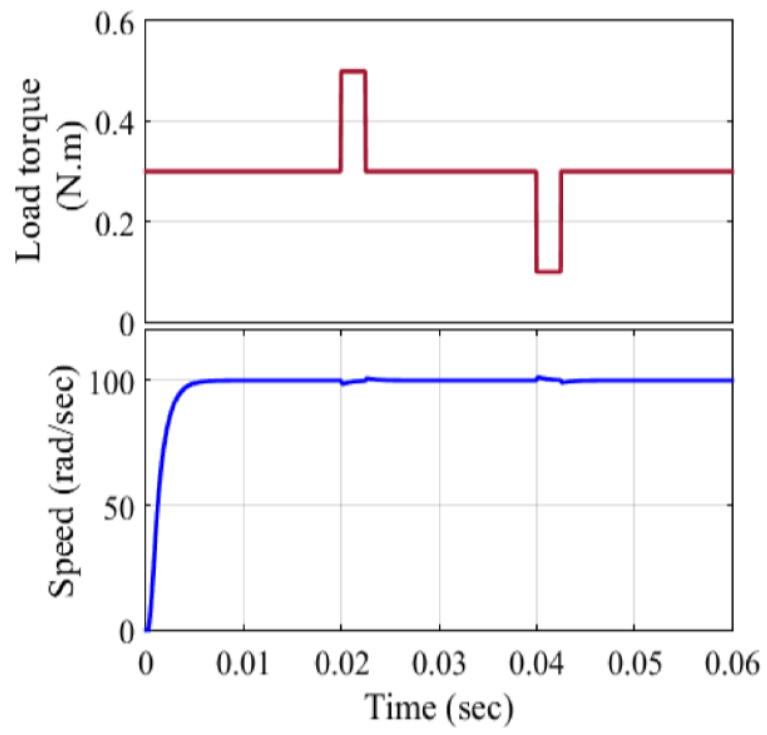

Fig. 8: The speed response under load disturbance. 


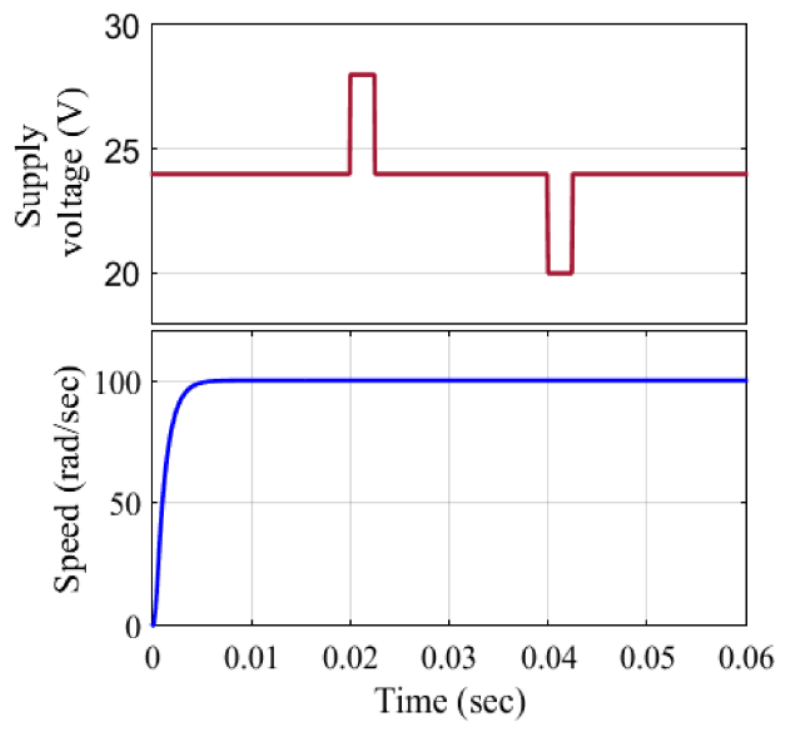

Fig. 9: The speed response under supply voltage disturbance.

While Fig. 9 shows the system response when $24 \mathrm{~V}$ supply voltage with $\pm 4 \mathrm{~V}$ disturbance. It is observed that the system response is unaffected.

To illustrate the system response and robustness of proposed control, the reference speed changed from $100 \mathrm{rad} / \mathrm{sec}$ to \pm 50 at every 20 msec, it can be notice that the system response tracking the reference speed exponentially and quickly, as shown in Fig. 10.

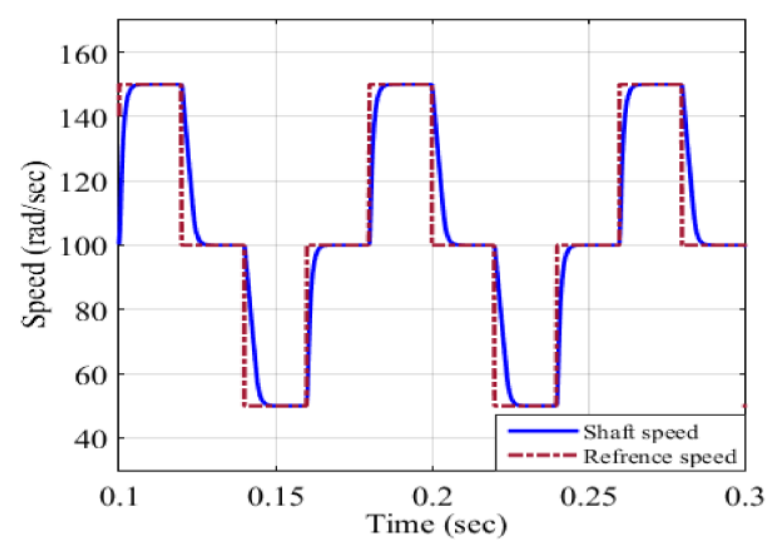

Fig. 10: The speed response under reference speed variation.

\section{CONCLUISION}

In this paper, the nonlinear dynamical analysis of PM DC motor drive has introduced. The dynamical features of the system have been illustrated by discussing the bifurcation diagram, time response and phase portrait. It has shown that the speed and current dynamics exhibit complicated oscillations when the supply voltage exceeds the critical value. The limit cycle, quasiperiodic, and chaotic oscillations can be observed.

The sliding mode control method is applied to the speed control, by the implementation at this control technique, it has notice that these irregular oscillations disappear even if the supply voltage exceeds the critical value, it is noticed that the chaotic oscillations successfully suppressed. A main feature of chaotic system is extreme sensitivity to small disturbance, from the result we confirmed that the proposed controller is robust to large disturbances effect.

\section{References}

[1] D. Gulick, Encounters with chaos, McGraw Hill, New York , 83-127, 1992.

[2] X. Li, W. Pan, B. Lou, and D. Ma " Chaos Synchronization and Communication of Cascade-Coupled Semiconductor Laser ", Journal of Light Wave Technology, Vol. 24, No:12,pp.4936-4945, 2006.

[3] E. Freier, L. Franquelo, and J. Aracil, "Periodicity and chaos in autonomous electronic system", IEEE Transactions On Circuit and Systems, Vol. CAS-31, NO: 3,pp.237-247, 1984.

[4] M. P. Kennedy, "Three step to chaos-part II: A Chua's circuit primer", IEEE Transactions On Circuits and Systems-I: Fundamentals Theory and Applications, Vol. 40, NO: 10, 657-674,1993.

[5] G. R. Rohde, J. M. Nicols, and F. Bucholtz, "Chaotic Signal Detection and Estimation based on Attractors Sets: Applications to Secure Communications", Chaos 18, 013114(2008).

[6] K. Chakrabarty, U. Kar, "Stabilization of unstable periodic orbits in DC drives", IEEE International Conference on Electrical 
Engineering and Information Communication Technology (ICEEICT), 2123 May 2015, pp. 1-6.

[7] K. Chau and Z. Wang, "Chaos in Electric Drive Systems: Analysis, Control and Application," First Edition, John Wiley \& Sons (Asia) Pte Ltd, 2011, ISBN 978-0-47082633-1.

[8] K. T. Chau, J. H. Chen, C. C. Chan, Jenny K. H. Pong, and D. T. W Chan, "Chaotic behavior in a simple DC drive," In proceeding of IEEE power electronics and drive systems, Singapore, 1997, pp. 473-479.

[9]M. H. Zadeh and A. Yazdian, M. Mohamadian "Robust Position Control in DC Motor by Fuzzy Sliding Mode Control ", IEEE International Conference on International Symposium on Power Electronics, Electrical Drives, Automation and Motion, 23-26 May 2006, pp. $1413-1418$.

[10]J. H. Chen, K. T. Chau, and C. C. Chan, "Analysis of chaos in current-mode-controlled DC drive systems," Industrial Electronics, IEEE Transactions on, Vol. 47, pp. 67-76, 2000.

[11] S. Ye and K. T. Chau, "Chaoization of DC Motors for Industrial Mixing", IEEE Transactions on Industrial Electronics, Volume:54, Issue: 4, Aug. 2007, pp. 2024 2032.

[12] T. Tang, M. Yang ,H. Li and D. Shen "A New Discovery and Analysis on Chaos and Bifurcation in DC Motor Drive System with Full-bridge Converter," IEEE International Conference on Industrial Electronics and Applications Conference , 24-26 May 2006, pp. 1 - 6.

[13] J. Chen, K. Chau, S. Siu, and C. Chan, "Experimental stabilization of chaos in a voltage- mode dc drive systems," IEEE Transactions on Circuits and Systems-I, vol. 47, July 2000, pp. 1093-1095.

[14] J. He, X. Zheng \& W. Wang, "Terminal Sliding Mode Control for Buck Converter with Chaos," IEEE International Conference on Power Electronics and Motion Control (IPEMC), 2-5. June. 2012, pp. 1532 - 1535.

[15] V. Utkin, J. Guldner and J. Shi, "Sliding mode control in electro-mechanical systems," $2^{\text {nd }}$ ed, Boca Raton, Fla.: CRC Press, 2009, ISBN 978-1-4200-6560-2.

[16] V. M. Panchade, L. M. Waghmare, B. M. Patre, P. P. Bhogle "Sliding mode control of dc drive," IEEE International Conference on Mechatronics and Automation, 5-8 Aug. 2007, pp. $1576-1580$. 